\title{
LUGARIZAÇÃO VIVIDA E A LOCALIDADE DO SER: UM RETORNO À GEOGRAFIA HUMANÍSTICA?
}

\author{
Lived Emplacement and the Locality of Being: A Return to Humanistic Geography? \\ Emplazamiento vivido y la Localidad del Ser: ¿Un Retorno a la Geografía \\ Humanística?
}

\section{David Seamon ${ }^{1}$}

Neste texto ofereço um relato em primeira pessoa sobre a geografia humanística que Cloke e seus colegas competentemente descrevem como a que "traz os seres humanos em toda a sua complexidade para o palco central da geografia humana" (Cloke et al, 1991: 58). Comecei meus estudos de pós-graduação em 1970 em um dos centros acadêmicos dos primeiros trabalhos humanísticos - o Programa de Pós-Graduação em Geografia da Clark University em Worcester, Massachussetts (Canter \& Craik, 1987). Fiz meu trabalho de doutorado sob orientação de Anne Buttimer, que foi reconhecida como uma das maiores figuras da geografia humanística (por exemplo Buttimer, 1971, 1974, 1976, 1993). Minha tese versou sobre a natureza da experiência ambiental cotidiana e foi publicada em 1979 como Uma Geografia do Mundo-da-vida: Movimento, Pausa e Encontro ${ }^{3}$ (Seamon, 1979).

Baseado parcialmente na minha experiência em Clark e nos esforços profissionais feitos desde então, neste texto eu discorro sobre como começou a geografia humanística, quais foram seus precedentes e se ela desempenha algum papel na pesquisa geográfica atual. Enfatizo o relato em primeira pessoa porque, muito frequentemente, mesmo sem intenção, as filosofias mais comuns da geografia retratam as mudanças conceituais da disciplina como temporalmente finitas. Retratam perspectivas filosóficas mais novas como se elas suplantassem as perspectivas precedentes que estão, elas mesmas, desaparecendo em grande medida (Johnston, 1997; Peet, 1998; Cresswall, 2013). Nestas interpretações padronizadas, dizem que a geografia humanística desapareceu principalmente em torno dos anos 1980 já que suas perspectivas e conclusões foram absorvidas, transformadas ou refutadas por pesquisas mais estruturais, marxistas e feministas. Na realidade, a motivação central e as preocupações temáticas da geografia

\footnotetext{
${ }^{1} \mathrm{O}$ texto traduzido do original "Lived Emplacement and the Locality of Being: A Return to Humanistic Geography?” é um primeiro rascunho de pré-publicação de um capítulo para Approaches to Human Geography, 2nd edition. Stuart Aitken and GillValentine, editors. London: Sage, 2014, forthcoming. (C) David Seamon, 2013. Sua tradução foi gentilmente autorizada pelo autor David Seamon.

2 "bringing human beigns in all of theis complexity to the centre-stage of human geography" (Cloke et al., 1991, p. 58).

${ }^{3}$ A Geography of the Lifewolrd: Movement, Rest and Encounter (Seamon, 1979).
}

Rev. Nufen: Phenom. Interd. | Belém, 9(2), 147-168, mai. - ago., 2017. 
humanística prosperam atualmente, apesar de ser mais usada por disciplinas e profissionais de fora da Geografia (Seamon, 2013b). Na última parte deste capítulo eu destaco alguns destes atuais desenvolvimentos e argumento que o objetivo e os princípios centrais da geografia humanística permanecem robustos e podem se tornar poderosos novamente à medida que jovens pesquisadores venham a questionar e reagir contra perspectivas pósestruturalistas, críticas e relacionistas que atualmente dominam a Geografia (Creswell, 2013; capítulos 10-13).

\section{Precedentes e pontos de partida para a Geografia humanística.}

Apesar da geografia humanista não ter se formalizado até os anos 1970, o espírito da abordagem foi tratado no trabalho de vários geógrafos que precederam este período. Os exemplos incluem o interesse de Alexander Von Humboldt nas interpretações artísticas das regiões geográficas mundiais (Bunske, 1981); as explicações sensoriais e perceptivas das paisagens naturais e humanas de Johannes Gabriel Granö (Granö 1929/1997); os gêneros de vida de Paul Vidal de La Blache (Buttimer, 1971); o foco na geosofia de J.K.Wright - o estudo do conhecimento geográfico subjetivo (Wright 1947); e a magistral descrição das diferenças e semelhanças das experiências geográficas, sua compreensão e a imaginação criativa dos seres humanos de David Lowenthal (Lowenthal, 1961). Todos estes pensadores procuraram formas de compreender o fenômeno geográfico assim como contribuíram para a ação humana, seu conhecimento e expressão estética assim como refletem e são reflexos dela.

Apesar de estes primeiros trabalhos terem focado nas experiências geográficas e seus significados, os geógrafos não conheceram formalmente as possibilidades de uma geografia humanística até o início dos anos 1970. As narrativas mais comuns sobre a disciplina explicam sua gênese por meio de um crescente desapontamento com a pesquisa quantitativa que, neste período, dominava a Geografia e definia a disciplina como uma "ciência espacial" preocupada com padrões espaciais mensuráveis e previsíveis assim como inter-relações que pudessem ser expressas no espaço terrestre (por exemplo, Cloke et al., 1991; Creswell, 2013). Na Clark University e em muitas outras instituições acadêmicas no início dos anos 1970, esta abordagem científica para a pesquisa geográfica foi fortemente questionada por estudantes e professores de pós-graduação, particularmente à medida que a Guerra do Vietnã e a agitação civil nas cidades americanas questionavam os modelos matemáticos de causa e efeito que alegavam explicar os fenômenos geográficos espacialmente.

A não ser para quem viveu os anos 1960 é difícil compreender o abrangente impacto desta década, uma vez que, aparentemente do dia para a noite, a liberdade individual, flexibilidade social e tolerância para com o outro superou o rígido 
conservadorismo, conformismo e provincialismo americano dos anos 1950. Expresso particularmente no ecletismo musical e fílmico da década, um esmagador e palpável ethos estava no ar em todos os lugares e tocou quase todas as pessoas, quer pessoal ou profissionalmente, ou ambos. Denis Wood, um estudante de doutorado na Clark University à época, descreveu como era este ethos:

[Eu não estou] sendo tolo quando insisto que $A$ Hard Day's Night- os Beatles em geral - e nossas descobertas das Supremes e James Brown e as Famous Flames e Chuck Berry - inacreditável em sua aparição na Clark - tiveram tanto a ver com [a Geografia d] a Clark como qualquer outra coisa. Não pelos filmes e músicas per se, apesar de serem cruciais, mas aquilo que eles sugeriam sobre o que era e poderia ser, sobre como poderia ser, sobre as possibilidades que existiam para mudanças, que existiam para ser: porque o que aconteceu na Clark...foi, mais que tudo, uma mudança de ares, um abrir de janelas, um estraçalhamento de tabus acadêmicos, uma iconoclastia de métodos... ${ }^{4}$ (Wood, 1987, p. 419).

Entre os geógrafos da Clark, esta energia vibrante de mudança invocou direções intelectuais contrastantes (Seamon, 1987). Um grupo de professores e estudantes adotou a filosofia marxista, buscando viabilizar as melhorias sociais por meio da compreensão de como espaço e lugar se relacionam com a estrutura econômica e o poder político (Peet, 2000 , p. 953). Um segundo grupo de professores e alunos trabalhou no que à época foi chamado de "percepção ambiental e geografia comportamental" (Craik \& Canter, 1987). Muito mais do que os geógrafos marxistas, este segundo grupo foi crucial para o desenvolvimento dos trabalhos humanísticos na Clark porque estes pesquisadores mudaram o foco de indicadores agregados mensuráveis de comportamentos espaciais e ambientais para o comportamento ambiental, este trabalho foi crucial para muitos de nós pós-graduandos, porque apontava para uma compreensão mais qualitativa e interpretativa das relações vividas pelas pessoas com seus mundos geográficos (Saarinen; Seamon \& Sell, 1984).

No outono de 1970, o mesmo semestre que ingressei na pós-graduação, Anne Buttimer chegou na Clark como pós-doutoranda (Buttimer, 1987). Ela rapidamente se tornou

\footnotetext{
4 “[I am not] being silly when I insist that A Hard Day's Night - the Beatles in general - and our discovery of the Supremes and James Brown and the Famous Flames, and Chuck Berry - unbelievable in his appearance at Clark - that these has as much to do with [Geography] at Clark as anything else, not the films and music per se, though they were crucial, so much as what they suggested about what was and what could be, about how it could be, about the possibilities that existed for change, that existed for being: for what happened at Clark... was above all else a change of air, an opening of windows, a smashing of academic taboos, an iconoclasm of methods... (Wood, 1987, p. 419)
}

Rev. Nufen: Phenom. Interd. | Belém, 9(2), 147-168, mai. - ago., 2017. 
uma importante colaboradora para o pensamento tanto do grupo marxista quanto do grupo da geografia comportamental. Baseando-se em seu domínio da filosofia continental e suas pesquisas anteriores sobre geógrafos humanistas franceses, Buttimer gerou entusiasmo para com os estudos fenomenológicos, existencialistas e críticos em Geografia. Durante a década de 1970 na Clark, ela desempenhou um importante papel contribuindo nas pesquisas de estudantes de doutorado que, eventualmente, produziriam trabalhos importantes relacionados a temas humanísticos e comportamentais (Buttimer \& Seamon, 1980). O ponto principal aqui é que a geografia humanística provavelmente não teria acontecido na Clark e em outras instituições sem o ethos questionador, a profunda abertura e a muito oportuna boa sorte espalhada dos anos 1960.

Depois de sua mercurial ascensão nos anos 1970, no entanto, a geografia humanística caiu em hibernação disciplinar nos anos 1980 e 1990, apesar de seu ponto de vista ter permanecido vivo em outras tradições acadêmicas. Antes de discutir este declínio e o potencial renascimento, entretanto, é importante introduzir os principais trabalhos em geografia humanística que surgiram neste notavelmente criativo início dos anos 1970.

\section{Trabalhos-chave em Geografia humanística, 1970-1974.}

Estimulado pela paixão intelectual e meticulosidade de Anne Buttimer, nós pósgraduandos da Clark acompanhamos cuidadosamente as pesquisas geográficas e correlatas que contribuíam para as preocupações humanísticas. Olhando para o período dos anos 1970, se reconhece que houve cinco geógrafos que contribuíram mais para este trabalho: Anne Buttimer, David Ley, Marwyn Samuels, Yi-Fu Tuan \& Edward Relph. Apesar da pesquisa em geografia humanística incorporar uma considerável variedade de abordagens conceituais que incluíam o idealismo (Guelke, 1971) e o pragmatismo (Smith, 1984), estes cinco geógrafos embasaram-se amplamente no existencialismo e na fenomenologia, sendo estas as duas abordagens conceituais mais próximas que sustentaram a maior parte da geografia humanística (Cloke et al, 1991, p. 68-80; Creswell, 2013, p. 111-112). Existencialistas exploram a natureza da existência humana para que as pessoas encontrem sentido e finalidade em suas vidas por meio de conhecimento fundamentado e da ação (Samuels, 1971, 1978). Os fenomenólogos descrevem e interpretam a natureza da experiência humana, particularmente suas dimensões nítidas e tácitas marcadas pelo que os fenomenólogos chamam de mundo-da-vida - a natureza subentendida da vida diária sobre a qual normalmente as pessoas não refletem atentamente (Buttimer, 1976; Finaly, 2011; Seamon, 2013b; Seamon \& Gill, 2014).

O primeiro trabalho importante relacionado à geografia humanística surgiu no outono de 1970 - o artigo de Edward Relph na Canadian Geographer , "Uma investigação

Rev. Nufen: Phenom. Interd. | Belém, 9(2), 147-168, mai. - ago., 2017. 
sobre as relações entre fenomenologia e geografia" (Relph, 1970). Relph descreve a natureza e os métodos da fenomenologia e afirma que "todo conhecimento vem do mundo da experiência e não pode ser independente daquele mundo" ${ }^{6}$ (Relph, 1970, p. 193). Ele sugeriu que a abordagem fenomenológica pode ser importante fornecendo "novas compreensões do entendimento das relações entre [os seres humanos] e a natureza" (Relph, 1970, p. 196). Ainda lembro vividamente a animada discussão que este artigo estimulou entre nós, pós-graduandos da Clark. Naquele tempo, a possibilidade de pesquisa qualitativas que lidavam com a experiência e o significado geográficos era uma ideia absolutamente original para jovens pesquisadores que foram ensinados a assumir que a Geografia era uma ciência quantitativa.

Um ano depois, na mesma revista, vários temas apresentados por Relph foram elaborados por Yi-Fu Tuan em seu artigo "Geografia, Fenomenologia e o estudo da Natureza Humana" (Tuan, 1971). Ele fez um panorama de muitas dualidades vividas relacionadas à experiência geográfica, incluindo "lar-deslocamento" e "palco-bastidor". Ele concluiu que uma abordagem fenomenológico-existencialista seria útil para os geógrafos porque "não estuda nem [os seres humanos] nem o mundo de forma abstrata, mas sim seres-no-mundo, que também é o grande foco do geógrafo" (Tuan, 1971, p. 191). Também naquele ano, Marwyn Samuels completou, na Universidade de Washington, sua provocante tese "Ciência e Geografia: uma apreciação existencial ${ }^{10 "}$ (Samuels, 1971). Este trabalho foi um dos primeiros esforços de um geógrafo para avaliar criticamente a afirmação científicopositivista de que "o real é necessariamente objetivo, quantitativo e cumpre as leis "11" (Samuels, 1971, p. 81). O problema, explicou Samuels, não é tanto que seres humanos não possam ser objetificados, mas que esta objetificação "Não pode lidar com a pessoa como um todo, apenas com fragmentos ${ }^{12 "}$ (Samuels, 1971, p. 97).

O próximo ano frutífero para os trabalhos humanísticos foi 1974, no qual David Ley publicou seu inovador estudo de lugar-urbano, A preta cidade interior como posto avançado de fronteira ${ }^{13}$ (Ley, 1974) e Anne Buttimer publicou Valores em Geografia ${ }^{14}$, trabalho que se baseou nos argumentos existencialistas e fenomenológicos para demonstrar como um conjunto particular de princípios e valores sempre fundamentam o conhecimento,

\footnotetext{
5 "An inquiry into Relations between Phenomenology and Geography" (Relph, 1970)

6 "All knowledge proceeds from the world of experience and cannot be independente of that world" (Relph, 1970, p. 193)

${ }^{7}$ New insights into understanding the relationships between [human beings] and nature" (Relph, 1970, p. 196).

8 "Geography, Phenomenology, and the study of human nature" (Tuan, 1971).

9 "studies neither ['human being'] in the abstract nor the 'world' in the abstract but '[human-being]-in-theworld" (Tuan, 1971, p. 191)

${ }^{10}$ Science and Geography: an existencial appraisal (Samuels, 1971)

11 "what is real is necessarily objective, quantitative, and law-abiding "(Samuels, 1971, p. 81).

12 "cannot deal with the whole [person], only with fragments" (Samuels, 1971, p. 97)

13 The black inner city as frontier outpost (Ley, 1974)

${ }^{14}$ Values in Geography (Buttimer, 1974)
}

Rev. Nufen: Phenom. Interd. | Belém, 9(2), 147-168, mai. - ago., 2017. 
apesar de frequentemente em um nível inconsciente de que acadêmicos e profissionais não estão sempre cientes, mas deveriam estar (Buttimer, 1974). Também em 1974, Yi-Fu Tuan publicou dois trabalhos importantes, o primeiro era um capítulo no Progress in Human Geography, "Espaço e Lugar: Perspectiva Humanística ${ }^{15}$ ". Este artigo incluiu a perspectiva de Tuan da identificação perceptiva de dois diferentes modos de lugar: os símbolos públicos $^{16}$, lugares de proeminência como a praça Trafalgar em Londres que pode ser compreendida no primeiro olhar; e os campos de cuidado $^{17}$, lugares como a nossa vizinhança, conhecida apenas por meio de prolongada experiência e tipicamente indistinta visual ou arquitetonicamente (Taun, 1974a, p. 236-245). O segundo trabalho importante de Tuan em 1974 foi Topofilia, um livro que explora a natureza vivida do lugar e tornou-se um de seus mais influentes trabalhos geográficos, usado especialmente como referência por acadêmicos fora da Geografia. Este trabalho contribuiria para a popularização do termo topofilila, pelo qual Tuan quer dizer o apego emocional e o amor pelo lugar (Tuan, 1974b; Manzo \& Devine-Wright, 2014, Seamon, 2014b).

\section{Trabalhos-chave em Geografia humanística, 1976-1978}

O ano de 1976 pode ser considerado como aquele que marca o ápice dos trabalhos em geografia humanística. Em "Compreendendo o Dinamismo do Mundo-davida ${ }^{18 ",}$, um artigo do Annals of the Association os American Geographers, Buttimer considerou como o conceito fenomenológico de mundo-da-vida pode colaborar na compreensão sobre o sentido de lugar, espaço social e os ritmos espaço-tempo (Buttimer, 1976). Ela argumentou que trazer a atenção consciente para a "dimensão pré-refletida e subententida da experiência, os significados inquestionáveis e determinantes rotineiros do comportamento ${ }^{19 "}$ pode facilitar "o aumento da auto-consciência - e viabilizar a empatia com os mundos das outras pessoas ${ }^{20 "}$ (Buttimer, 1976, p. 281). Ainda nesta edição do Annals estava a "Geografia Humanística" de Yi-Fu Tuan, um artigo que forneceu a primeira formalização abrangente da perspectiva humanística, no qual o argumento de Tuan pode ter contribuído para aumenta o "nível de consciência" da sociedade (Tuan, 1976, p. 266). Ele concluiu que a primeira força do geógrafo humanístico é viabilizar uma melhor compreensão da condição humana em relação às preocupações geográficas.

\footnotetext{
${ }^{15}$ Space and Place: Humanistic Perspective (Tuan, 1974)

${ }_{17}^{16}$ public symbols

${ }^{17}$ fields of care

${ }^{18}$ Grasping Dynamism of Lifeword (Buttimer, 1976)

19 "prereflective, taken-for-granted dimensions of experience, the unquestioned meanings, and routinizes determinants of behavior" (Buttimer, 1976, p. 281)

20 "heightened self-awareness---and enable one to empathize with the worlds of other people" (Buttimer, 1976, p. 281)
}

Rev. Nufen: Phenom. Interd. | Belém, 9(2), 147-168, mai. - ago., 2017. 
O mais significativo trabalho em geografia humanística a ser publicado em 1976 foi o Lugar e Lugar-sem-lugaridade ${ }^{21}$ de Edward Relph, uma fenomenologia existencial do lugar, que ele definiu como a fusão da ordem humana e natural e qualquer centro privilegiado da experiência vivida de uma pessoa ou grupo (Relph, 1974, p. 141). De todos os trabalhos humanísticos em geografia dos anos 1970, este livro teve a influência mais duradoura porque marca o ponto-chave existencial da experiência de lugar em termos de insideness e outsideness - o grau da sensação de pertencimento e identificação de uma pessoa ou grupo com o lugar, por lado; ou um senso de alienação e ruptura por outro lado (Relph, 1976, p. 49-55; Seamon, 2008). Relph também introduziu o termo lugar-semlugaridade, que ele descreveu como a "erradicação casual de lugares distintos e a criação de paisagens padronizadas que resultam em uma insensibilidade para o sentido de lugar ${ }^{22}$ (Relph, 1976, p. ii).

O fim da primeira fase da geografia humanística é marcada pela publicação de Ley e Samuels em 1978, Geografia Humanística ${ }^{23}$, uma coleção editada demonstrando a considerável abrangência conceitual e de tópicos que as perspectivas humanísticas podiam oferecer à geografia (Ley \& Samuels, 1978). Em sua introdução, os editores enfatizaram como o foco na experiência humana e seu significado abrigou novas luzes disciplinares no modo como o espaço material torna-se um lugar significativo e como compreensões interpretativas pressupõem e explicitam uma "visão holística da geografia humana ${ }^{24 " ~(L e y ~ \& ~}$ Samuels, 1978, p. 11). Eles concluem:

Como [seres humanos] e ambiente contectam-se um ao outro dialeticamente, não há espaço na perspectiva humanística para um conceito passivo [de pessoa] diligentemente consentindo com um ambiente dominador. Mas nem [as pessoas] são totalmente livres, uma vez que [elas herdam] condições estruturais dadas e, de fato, pode não estar conscientes da completa extensão de [sua] ligação ${ }^{25}$ (Ley \& Samuels, 1978, p. 12)

\section{O exílio da Geografia humanística}

Na ponderação de Ley e Samuels de que os homens não são totalmente livres em função de fatores estruturais, é possível reconhecer uma crítica chave que contribuiria

\footnotetext{
${ }^{21}$ Place and Placelessness (Relph, 1976)

22 "casual eradication os distinctive places and the making os standardized landscapes that results from na insensitivity to the significance of place" (Relph, 1976, p. ii)

${ }^{23}$ Humanistic Geography (Ley \& Samuels, 1978)

24 "holistic vision of human geography" (Ley \& Samuels, 1978, p. 11)

25 "As [human beings] and environment engage each other dialectically, there is no room in a humanística perspective for a passive concept of [people] dutifully acquiescing to an overbearing environment. But neither [are people] fully free, for [they inherit] given structural conditions and, indeed, may be unaware of the full extent of [their] bondage" (Ley \& Samuels, 1978, p. 12).
}

Rev. Nufen: Phenom. Interd. | Belém, 9(2), 147-168, mai. - ago., 2017. 
para o declínio da geografia humanística - sua aparente relutância em lidar com forças estruturais sociais mais amplas que preparam o palco para a experiência humana e seu significado. Apesar de terem sido publicados vários volumes importantes em geografia humanística entre os anos 1980 e 2000 (por exemplo, Adams et al., 2000; Buttimer, 1993; Buttimer \& Seamon, 1980; Entrikin, 1991; Relph, 1981; Sack, 1997; Seamon, 1993; Seamon \& Mugerauer, 1985; Tuan, 1982, 2012), geógrafos marxistas e feministas começaram a questionar os princípios humanísticos nos anos 1980 (Cloke et al., 1991; Creswell, 2013; Peet, 1998; Rose, 1995; Seamon \& Sowers, 2008, p. 670-671). A crítica subentendida de Ley \& Samuels e feita de modo direto por geógrafos marxistas era de que a geografia humanística enfatizava o agenciamento humano individual e ignorava as estruturas econômicas e políticas mais amplas que moldavam mundos-da-vida e lugares. Uma segunda crítica trazida à luz tanto por geógrafos marxistas quanto feministas, era de que a geografia humanística era essencialista - ou seja, assumia uma condição humana universal compreendida apenas quando todas as qualidades "contingentes" como a história e a cultura eram colocadas de lado, revelando uma estrutura central e invariável da experiência humana e seu significado. Uma terceira crítica, apontada por geógrafas feministas, era de que o trabalho humanístico incorporava uma perspectiva implicitamente masculina uma vez que assumia que a experiência de acadêmicos profissionais, em sua maioria homens, poderia representar e conhecer todas as situações humanas. Geógrafas feministas argumentavam que não há "seres humanos universais" como os geógrafos humanistas pareciam querer. Estas críticas sustentavam que o foco mais importante deveria ser as experiências e situações de desvantagem, marginalidade e menor poder de indivíduos e grupos que a pesquisa geográfica convencional muito frequentemente não compreendeu ou ignorou - por exemplo, mulheres, crianças, gays e lésbicas, portadores de deficiência, desabrigados e assim por diante.

No período, estas e outras críticas foram respondidas apenas de modo fragmentado (ex. Duncan \& Ley, 1984; Seamon, 1982), e nenhum geógrafo humanístico produziu ou sustentou contra argumentos para refutar as preocupações marxistas ou feministas. Em retrospecto, baseado no desenvolvimento do pensamento fenomenológico e hermenêutico desde os anos 1980, podemos ver mais claramente como estas críticas à geografia humanísticas poderiam ter sido rebatidas. A primeira acusação de essencialismo não compreendeu o reconhecimento humanístico que há diferentes dimensões da experiência humana e da existência que devem ser consideradas em um entendimento completo da experiência geográfica e seu significado. Por um lado, todos os seres humanos são únicos e a perspectiva humanística pode prontamente dar atenção para as dimensões vividas do indivíduo relacionadas ao gênero, sexualidade, grau de deficiência e assim por diante (Finaly, 2011; Simms \& Stawarska, 2013; Toombs, 2001). Ao mesmo tempo, a 
perspectiva humanística pode lidar com experiências ambientais e seus significados à medida que elas se relacionam com a história, situação social ou cultural particular de uma pessoa ou grupo - por exemplo, o período e local no qual a pessoa vive, suas circunstâncias políticas e econômicas, e seu contexto educacional, religioso e social (ex. Finlay, 2011; Murton, 2012; Simms, 2008; Sowers, 2010). Esta habilidade conceitual e metodológica para examinas as várias diferentes dimensões da vida humana e seus significado demonstra que a geografia humanística pode se mover para além das características do "homem" e dos "seres humanos" denominadas "universais" ou "essenciais" criticadas pelas feministas. A perspectiva humanística pode explorar mundosda-vida específicos e situações vividas em particular; na pesquisa fenomenológica atual, por exemplo, é possível encontrar sub-especialidades como "fenomenologia feminista", "fenomenologia dos portadores de deficiência", "fenomenologia das crianças", "fenomenologia da mobilidade", "fenomenologia dos desabrigados", e assim por diante (ex. Finlay, 2011; Moores, 2012, Simms \& Stawarska, 2013).

Mais difícil de refutar é a crítica marxista de que o trabalho humanístico favorece o agenciamento humano em detrimento da estrutural societária e seria, então, voluntarista ou seja, ela tacitamente vê a sociedade e o mundo como um produto de ações intencionais e voluntárias de indivíduos ou de agenciamento humano autônomo. Assumindo em grande parte uma perspectiva que enfatiza a autoconsciência como veículo para a mudança pessoal e social, os geógrafos humanísticos de fato deram mais atenção para a experiência, compreensão e liberdade individuais. Por um lado, a geografia humanística tipicamente envolve uma suposição ideológica subjacente de que a vontade individual e o crescimento pessoal fornecem mais formas para fazer a diferença no mundo de forma mais ampliada, incluindo mudanças sociais e políticas construtivas. Por outro lado, o trabalho humanístico pode examinar fenômenos tais como poder, exclusão, resistência, justiça e processos políticos, apesar de pouco trabalho ter sido feito nesta direção nos anos 1970, talvez porque a maior parte dos geógrafos humanísticos instintivamente favoreceu a experiência, a individualidade e autonomia pessoal e de grupo. Mais recentemente, tem havido alguns esforços "humanísticos" para considerar preocupações estruturais e ações políticas - por exemplo, os geógrafos Soren Larsen e Jay Johnsons (2012) usam de um conceito de lugar revigorado para viabilizar a ação comunitária, ou o teórico político Daniel Kemmi (1990, 1995) que considerou como o sentido cidadão da responsabilidade pelo lugar no qual se vive pode viabilizar uma política civilizada.

No entanto, as críticas feministas e marxistas dos anos 1980, sobre o essencialismo, masculinismo e voluntarismo provavelmente levaram muitos geógrafos a abandonar o trabalho humanístico. Tristemente, Cresswell está certo quando escreveu recentemente que "poucos geógrafos atualmente referem-se a si mesmos como 
humanísticos $^{26 "}$ (Creswell, 2013, p. 119). Ironicamente, começando nos anos 1990, nãogeógrafos deram renovada atenção para tópicos humanísticos como lugar (Casey, 2009; Kogl, 2008; Malpas, 1999; Moores, 2013; Mugerauer, 1994; Stefanovic, 2000), lar e habitar (Ingold, 1995; Malpas, 2008; Mugerauer, 2008); paisagem (Lane, 2000; Tilley, 2008); encontro ambiental e ética (Bortoft, 1996; Brown e Toadvine, 2003; Cataldi \& Hamrick, 2007; Geib, 2007; Seamon \& Zajonc, 1998), e design ambiental e política como criadores de lugares (Alexander, 2012; Davis, 2012; Kemmis, 1995). Para sugerir como estes trabalhos podem contribuir para uma geografia humanística rejuvenescida, me baseio no exame de pesquisas recentes sobre as dimensões vividas do lugar. Enfatizo o trabalho fenomenológico porque esta abordagem conceitual sustenta a maior parte dos trabalhos mais recentes sobre lugar.

\section{A localidade do ser}

A abordagem humanística do lugar nos anos 1970 foi amplamente subjetivista à medida que o lugar era interpretado como uma representação subjetiva, cognitiva ou afetiva, dentro de experienciadores e ontologicamente distintas de um ambiente externo objetivo. Como filósofo fenomenólogo Jeff Malpas (1999, p. 30) destacou que esta abordagem subjetivista é ontologicamente insuficiente porque "não fornece explicação real do conceito de lugar já que meramente junta a ideia de uma parte do espaço físico objetivo com a qualidade emocional subjetiva ou afetiva ou um conjunto de qualidades de modo que trata o

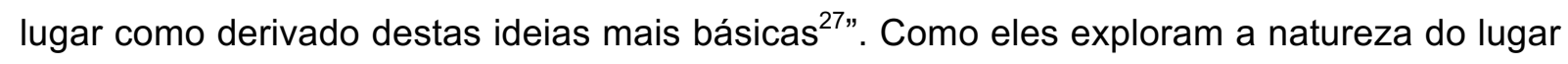
nos anos 1990 e 2000, Malpas (1999, 2008, 2009) e o filósofo fenomenólogo Edward Casey (1997, 2009) argumentam que o lugar deve ser entendido como uma estrutura ontológica primária que inclui tanto a experiência humana quanto o mundo material no qual a experiência acontece. Como Casey afirmou sucintamente "Quem nós somos reflete muito onde estamos $^{28 "}$ (2001b, p. 226). Ou como Malpas explicou mais completamente,

O que somos como seres que vivem, pensam, experimentam é inseparável dos lugares onde vivemos - nossas vidas estão saturadas pelos lugares e pelas coisas e outras pessoas entrelaçadas a estes lugares, pelos quais nos movemos

\footnotetext{
26 "Few geographers now refer to themselves as humanistic" (Creswell, 2013, p. 119)

27 "it provides no real explication of the concept of place as such, since it merely conjoins the idea of a part of objective physical space with the subjective emotional or affective quality or set of qualities and so treats place as derivative of these more basic ideas" (Malpas,1999, p. 30).

28 "Who we are very much reflects where we are" (Casey, 2001b, p. 226).
} 
e nos quais nossas ações estão localizadas e a respeito do qual estamos orientados e nos localizamos ${ }^{29}$ (Malpas, 2011, p. 231).

Esta contenda de que o ser do homem é sempre ser-no-lugar - a "localidade do ser $^{30 ", ~ c o m o ~ M a l p a s ~}(1999,8, \mathrm{n} 30)$ denominou - marca um radical desenvolvimento no pensamento geográfico porque pressupõe que "a possibilidade do aparecimento das coisas - de objetos, do ser e de outros - é possível apenas dentro do abrangente compasso do lugar ${ }^{31 "}$ (Malpas, 1999, p. 15). Se o mundo se apresenta apenas por meio do lugar, então este fator vivido significa que as conexões humanas com o lugar não são contingentes, acidentais ou determinadas por construtos sociais ou políticos mais primários (Malpas, 1999, p. 29-33). Ao contrário, ser humano é sempre estar lugarizado "é por meio de nosso envolvimento com o lugar que nossa própria humanidade torna-se real, mas é também por meio de nosso envolvimento que o lugar se forma em um sentido e um significado próprio 32 " (Malpas, 2009, p. 33).

Não posso enfatizar o suficiente o quanto este entendimento conceitual e prático da lugarização vivida é potencialmente transformador. O lugar é poderoso porque, só por ser o que é, ele junta o mundo espacial e ambientalmente, delineando centros da ação humana, seus significados e intenções que, por outro lado, contribuem na formação do lugar. Esta conceitualização significa que o lugar não é um ambiente físico separado das pessoas associadas a ele, mas ao contrário, é indivisível a geralmente desconsiderada situação da experiência-de-lugar-das-pessoas. Este fenômeno é complexo, dinâmico e incorpora processos generativos pelos quais o lugar e suas experiências e significados mudam ou permanecem os mesmos (Seamon, 2013b, 2014b). Esta lugarização vivida também significa que a qualidade da vida humana está intimamente relacionada à qualidade de lugar no qual esta vida se desdobra e vice-versa. Como Malpas explica:

Como a vida é de fato constituída em e através de sua relação com os lugares nos quais ela é vivida, também a riqueza desta vida e o desenvolvimento de um sentido de seu próprio caráter unitário e auto identidade, ela está diretamente conectada com o modo pelo qual as relações vividas com o lugar articulam-se e expressam esta mesma vida. Neste caso, para viver de um modo negligente do lugar seria viver em um modo que negligencia aquela própria vida - seria como

\footnotetext{
29 "what we are as living, thinking, experiencing beings is inseparable from the places in which we live - our lives are saturated by the places, and by the things and other persons intertwined with those places, through which we move, in which our actions are located, and with respect to which we oriente and locate ourselves (Malpas, 2011, p. 231)

${ }^{30}$ Locality of being

31 "The very possibility of the appearance of things - of objects, of self, and of others - is possible only within the all-embracing compass of place" (Malpas, 1991, p. 15)

32 "It is through our engagement with place that our own human being is made real, but is also through our engagement that place takes on a sense and a significance of its own" (Malpas, 2009, p. 33)
}

Rev. Nufen: Phenom. Interd. | Belém, 9(2), 147-168, mai. - ago., 2017. 
viver de um modo que provavelmente levaria a um empobrecimento e talvez até um modo de existência fragmentado. Cuidar e tratar de nossa própria vida, deste modo, demanda que também cuidemos e tratemos do lugar $^{33}$ (Malpas, 2001, p. 232).

Como uma forma de entender o sentido da lugarização vivida mais profundamente, alguns fenomenólogos baseiam-se no conceito de corpo vivido - um corpo que simultaneamente experiencia, age e negocia um mundo que, tipicamente, responde com significacão imediata e presença contextual (Casey, 2009; Finlay, 2011; Seamon, 2013a, 2014a; Toombs, 2001). No que diz respeito à lugarização vivida, fenomenólogos reconhecem que o corpo vivido é um constituinte essencial do lugar e a experiência de lugar porque "corpos vividos pertencem a lugares e ajudam a constituí-los ${ }^{34 "}$ assim como, simultaneamente "lugares pertencem aos corpos vividos e dependem deles ${ }^{35 "}$ (Casey, 2009, p. 327). Por meio de ações e encontros do corpo, as pessoas ou grupos contribuem para o sentido de envolvimento vivido e identificação com o lugar das pessoas ou grupos. Em resumo, corpos vividos e lugares "interanimam um ao outro"36" (Casey, 2009, p. 327).

Esta interanimação dos corpos vividos e lugares é significativa porque ela sugere que a familiaridade habitual e inconsciente dos corpos vividos é um modo pelo qual indivíduos e grupos atualizam o subestimado envolvimento com o lugar (Seamon, 2013a). A este respeito está a possiblidade de que, em um ambiente físico solidário, as rotinas corporais dos indivíduos podem se juntar no tempo e no espaço, desta forma contribuindo para um conjunto ambiental em larga escala, ou balé do lugar - uma interação de rotinas corporais individuais enraizada em um ambiente em particular, que frequentemente torna-se um lugar importante de trocas interpessoais e comunais e apego, por exemplo, um café popular no bairro ou uma parte vibrante de uma rua da cidade (Fullilove, 2004; Oldenburg, 1999; Seamon, 1979, 2012, Simms, 2008). O balé do lugar aponta para a possibilidade de que rotinas habituais cotidianas que regularmente se desdobram em um espaço físico podem transformar aquele espaço em um lugar vivido com um caráter e ambiente únicos (Moores, 2012, p. 52-56). Pode-se também considerar como os habituais corpos dos indivíduos e grupos são atraídos uns para os outros ou afastados por estas características

\footnotetext{
33 "Since life is indeed constituted in and through its relation to the places in which it is lived, so the richness of that life, and the development of a sense of its own unitary character and self-identity, is directly tied to the way in which the lived relation to place comes to be articulated and expresses in that life. In that case, to live in a way that is neglectful of place will be to live in a way that is neglectful of that life itself - I will be to live in a way likely to give rise to an impoverished and perhaps even fragmented mode of existence. To care for and attend to our own lives thus demands that we also care for and attend to place" (Malpas, 2001, p. 232)

34 "lived bodies belong to places and help constitute them" (Casey, 2009, p. 327)

35 "places belong to lived bodies and depend on them" (Casey, 2009, p. 327).

36 “interanimate each other" (Casey, 2009, p. 327)
}

Rev. Nufen: Phenom. Interd. | Belém, 9(2), 147-168, mai. - ago., 2017. 
ambientais tais como formas arquitetônicas e escala (Alexander, 2012, Davis, 2013) e a configuração espacial dos caminhos (Hillier, 1996; Seamon, 2004, 2012, 2013a).

\section{Críticas da lugarização vivida}

Apesar da "lugarização vivida" delineada por Edward Casey e Jeff Malpas ser uma nova maneira relevante de compreender a importância singular do lugar na vida humana, poucos geógrafos até agora consideraram suas implicações teóricas e práticas (Entrikin, 2001; Hooper, 2001; Massey, 2005, p. 183-184). Em sua grande introdução ao lugar, Tim Creswell (2004) reconheceu as enormes diferenças entre a compreensão fenomenológica de lugar como "a localidade do ser" e a compreensão social-construtivista, na qual o lugar é reduzido a pouco mais que um produto secundário de processos sociais mais primários (Creswell, 2004, p. 30). Ele conclui, no entanto, que as explicações

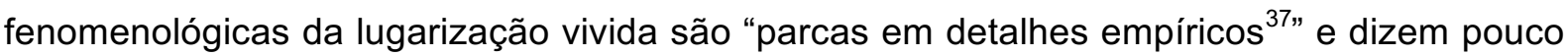
"sobre os processos que fizeram um lugar o que ele é ${ }^{38 "}$ (Creswell, 2004, p. 32). As preocupações de Creswell aqui são legítimas, e há necessidade de explorar a lugarização vivida de maneiras fenomenológicas onde uma compreensão das experiências vividas, significados e dinâmicas do lugar estejam localizados nas qualidades do próprio lugar ao invés dos processos sociais, econômicos, políticos, culturais de gênero ou discursos identificados como centrais no social-construtivismo e nas compreensões críticas do lugar.

As pesquisas das estruturas experimentais e dinâmicas da lugarização vivida começaram apenas recentemente, mas exemplos de suas consequências já podem ser apontados: os fenomenológicos Anthony Steinbock (1995) e Janet Donohoe (2010) usam a explicação de Edmund Husserl sobre "mundo familiar" (homeworld) e "mundo estranho" (alienworld) para gerar uma dialética vivida do lugar (Seamon, 2013c); a filósofa Ingrid Leman Stefanovic (2000) repensa a sustentabilidade por meio do conceito de lugar; as pesquisas da psicóloga Eva Simms (2008) sobre as mudanças do sentido de lugar e as dinâmicas espaço-tempo em uma vizinhança desprivilegiada em Pittsburgh; o geógrafo Edward Relph delineou o "espírito de lugar" versus o "sentido de lugar" (Relph, 2009); a fenomenologia de Wonder Valley, do geógrafo Jacob Sowers, sobre uma comunidade remota no sul da Califórnia habitada por três grupos contrastantes de residentes identificados como "proprietários", "distópicos" e "utópicos" (Sowers, 2010); os esforços dos geógrafos Soren Larsen e Jay Johnson (2012) para conectar uma ontologia baseada no lugar com afinidades políticas; o geógrafo Brian Murton (2012) usou o "ser geográfico" para aprofundar a compreensão sobre a personalidade, paisagem e lugar dos Mãori; e minha tentativa (Seamon, 2014b) de identificar uma rede interconectada de processos generativos

\footnotetext{
37 "Short on empirical detail" (Creswell, 2004, p. 32)

38 "about the processes that went into making [a] place what it is" (Creswell, 2004, p. 32).
}

Rev. Nufen: Phenom. Interd. | Belém, 9(2), 147-168, mai. - ago., 2017. 
pelos quais os lugares evoluem, transferem ou permanecem mais ou menos os mesmos. Todos estes trabalhos procuram destacar estruturas descritivas e inter-relações originalmente surgidas de experiências do mundo real e úteis para a compressão de uma lugarização mais amplamente vivida e fenômenos geográficos relacionados com a sensação de estar no lar, apego à comunidade e identidade, sensação de estar fora do lugar, personalidade ambiental, e processos que sustentam ou debilitam a moldagem do lugar.

\section{Lugar estático ou exclusivo?}

Se a ontologia baseada no lugar de Malpas e Casey vai ganhar tração conceitual na Geografia é uma questão que pesquisadores futuros irão responder. Atualmente, as preocupações críticas, pós-estruturalistas e social-construtivistas relacionadas ao lugar estão muito mais focadas em saber como lugares contemporâneos do mundo real incorporam ou ultrapassam as qualidades existenciais alegadas pelas interpretações humanísticas e fenomenológicas de lugar (Seamon, 2013b; p. 160-163). Um grupo de críticos argumenta que estas interpretações muito rapidamente enfatizam os aspectos centralizadores e exclusivistas do lugar (Creswell, 2004, p. 18-26; Massey, 1991, 2005; Rose, 1993, p. 41-61). Estas críticas são parcialmente corretas no sentido de que os primeiros estudos fenomenológicos do lugar nos anos 1970 e 1980 basearam-se fortemente nos filósofos fenomenólogos da primeira geração como Gaston Bachelard (1964) e Martin Heidegger (1971), que conceituaram amplamente o lugar como estático, limitado, conservador e paroquial. Críticas sobre essa perspectiva de lugar inerte e contido falam, ao contrário, de um "sentido progressista de lugar"39" (Massey, 1991, p.29). Eles questionam como os lugares se relacionam e respondem aos seus contextos social, econômico e geográfico mais amplo. Para estes críticos, os lugares permanecem importantes, mas a necessidade conceitual e prática mais relevante seria delinear as formas pelas quais os lugares particulares tornam-se mais interconectados e porosos em relação aos outros lugares. Como, em outras palavras, o lugar pode incorporar diversidade, a integração de diferenças, e relacionamentos construtivos com outros lugares? O objetivo é "uma visão externa política do lugar para além do lugar ${ }^{40 " ~(M a s s e y, ~ 2005, ~ p . ~ 192) . ~}$

Um segundo grupo de críticos alega que, por causa de tendências atuais em direção á globalização e realidades virtuais, os lugares do mundo real são, de várias maneiras, marginais e obsoletos. Estas críticas questionam a inércia rígida e imutável descrita nos relatos humanísticos. Ao contrário, eles falam de movimentos mutantes e fluxos entre lugares, ideias, pessoas e estados-nação. Estes críticos favorecem a mobilidade, hibridismo, fluxo, não-lugares, hiper-mundos e heterotopias. Baseado no trabalho dos

\footnotetext{
39 "progressive sense of place" (Massey, 1991, p.29).

40 "a politics of outwardlookingness from place beyond place" (Massey, 2005, p. 192)
}

Rev. Nufen: Phenom. Interd. | Belém, 9(2), 147-168, mai. - ago., 2017. 
filósofos pós-estruturalistas Giles Deleuze e Félix Guatarri (1987), um conceito central é o rizoma - uma estrutura geográfica-espacial de fluxos livres e imprevisíveis e movimentos gerando redes descentralizadas que ignora amplamente limites e contingências (Kogl, 2008, p. 57-77).

Apesar desta crítica pós-estruturalista provocar o pensamento, um geógrafo humanístico pode responder destacando que, mesmo que a globalização e os fluxos deteriorem alguns lugares hoje em dia, os mesmos processos fortalecem outros lugares e viabilizam novos tipos de lugares. Mais importante, os lugares mantém a importância porque "o corpo humano é sempre local, viver uma vida particular em um lugar particular, com outros, para bem e para mal ${ }^{41 "}$ (Kogl, 2008, p. 143). Neste sentido, o lugar permanece um dos grandes estabilizadores constituintes da vida humana naquilo que automaticamente mantém corpos vivos no lugar e, portanto, fornece um tipo de ordem espacial e identidade ambiental. A não ser que a vida humana torne-se inteiramente virtual, não material e de segunda mão pela continuidade dos desenvolvimentos nas tecnologias digitais e robóticas, os lugares permanecerão uma parte dos seres humanos. Apesar de nem todos os indivíduos ou grupos serem igualmente identificados e ligados ao lugar de suas vidas, aqueles lugares ainda são integrais no sentido de que eles sempre forneceram o cotidiano, o subestimado contexto espacial e ambiental para o mundo-da-vida de cada pessoa ou grupo, ao menos em termos de personificação ambiental.

Esta inescapável corporeidade do lugar é frequentemente ignorada pelo primeiro grupo de críticos do lugar que procuram um sentido de lugar mais progressista. Estes críticos estão corretos de que, na nossa era pós-modernista, devemos localizar formas pelas quais a inércia de lugares particulares pode ser revigorada e, em retorno, revigorar outros lugares por meios de uma exuberante interconectibilidade que viabiliza a diversidade e contribui para a aceitação da diferença. Mas uma boa parte de tais trocas e dinâmica permanecerá embasada na habitual regularidade dos corpos lugarizados. Estes críticos também não podem desconsiderar a realidade de que a dinâmica de troca entre os lugares pressupõe uma robusta integração de cada lugar nele mesmo, estas robusta integração é pelos menos em parte, fundada na regularidade inercial de corpos vivos no espaço físico.

Neste sentido, os lugares físicos muito provavelmente manterão um papel central na vida humana, e alguém pode se perguntar como, no nosso mundo hipermoderno, a produção inconsciente do lugar do passado pode se regenerar de modo autoconsciente, por meios de cuidadoso planejamento, política justa e design criativo (Alexander, 2012; Davis, 2012; Kemmis, 1995, Seamon, 2004, 2013a; 2014a)?

\footnotetext{
41 "the human body is Always local, living a particular lifer in a particular place, with others, for better or worse" (Kogl, 2008, p. 143)
}

Rev. Nufen: Phenom. Interd. | Belém, 9(2), 147-168, mai. - ago., 2017. 


\section{Uma humildade ambiental}

Neste capítulo, argumentei que a tradição humanística em Geografia refere-se a uma perspectiva conceitual e ética particular no que se refere ao que a compreensão culta deveria ser: uma descoberta progressista da natureza da vida humana, sua experiência e seus significados em relação a fenômenos geográficos tais como espaço, lugar, paisagem, região e os ambientais naturais e humanos. Vital a este estilo de compreensão é o sentido de maravilhamento pelo fenômeno geográfico do mundo assim como um desejo de compreendê-los como eles são por seu próprio direito sem ter que prestar atenção a nenhuma obrigação conceitual, ideológica ou prática. $\mathrm{O}$ impulso desta pesquisa deriva da vontade de conhecer, da satisfação de saber e do prazer intelectual e emocional em encontrar maneiras de explorar o fenômeno no qual se está interessado. Esta forma de compreender incorpora o autoconhecimento, já que por meio do estudo da natureza vivida do lugar, espaço e ambiente, nós descobrimos mais sobre nós mesmos. Talvez nos tornemos melhores seres humanos por causa deste entendimento. Movemo-nos para o que Relph definiu perspicazmente como humildade ambiental - uma forma de viver em, estar com e encontrar o mundo por meio dos "outros" daquele mundo, sejam eles coisas, lugares, pessoas ou outros seres vivos, dizem respeito apenas a ser o que são e, deste modo, são colocados em primeiro lugar e recebem gentil atenção (Relph, 1981, p. 161-167). Humildade ambiental envolve:

Um apelo pela tutela, pelo cuidado com as coisas meramente porque elas existem, por tratar e protege-las. Isto não é nem domínio nem subserviência, mas há responsabilidade e compromisso ${ }^{42}$ (Relph, 1971, p. 187).

O modo aberto e empático de compreender as coisas, que a humildade ambiental cultiva é consideravelmente diferente das atuais abordagens críticas, pósestruturalistas e relacionistas que negam quaisquer estruturas fundantes e generativas apoiando a realidade vivida da vida cotidiana (Creswell, 2013, capítulos 10 - 13). A busca humanística pela ordem, unidade, síntese, generalização e verdade é substituída pelo foco pós-estruturalista na indeterminação, diversidade, narrativas locais, particularidades e possibilidades contingentes (Rosenau, 1992). As geografias pós-estruturalistas, críticas e relacionistas rejeitam padrões externos de racionalidade e confiabilidade; ao contrário, qualquer alegação pela validação ou acurácia é considerada provisória, local e não mais

\footnotetext{
42 "an appeal for guardianship, for taking care of things merely because they exist, for tending and protecting them. In this there is neither mastery nor subservience, but there is reponsability and commitment" (Relph, 1971, p. 187).
} 
correta ou real do que qualquer outra. Como Rosenau afirma "não há verdade, e tudo está em construção ${ }^{43 "}$ (Rosenau, 1992, p. 90).

Relph relata que, quando Mahatma Ganghi foi perguntado sobre o que mais o preocupava, ele respondeu, "a dureza do coração dos instruídos ${ }^{44 " ~(R e l p h, ~ 1981, ~ p . ~ 107) . ~}$ Esta é provavelmente a questão central para uma geografia humanística revigorada: como nós evocamos um compromisso solidário e emocional de modo que nossas explicações dos fenômenos geográficos sejam generosas, sinceras, acuradas e vivas? Relph escreve que a necessidade é "um modo de ver que se empenha em não omitir nada e, no entanto, não impõe nada. Ele pega o mundo todo como ele é dado, e trata-o cuidadosamente para a

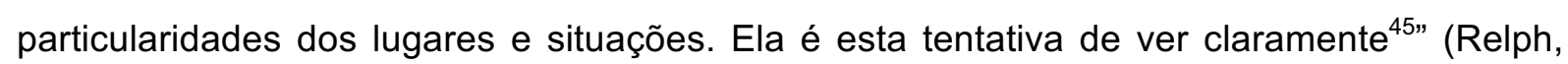
1981, p, 177). Este modo de compreender envolve caridade, elegância, respeito e resiliência. Seu ímpeto abasteceu a geografia humanística nos anos 1970. Ela pode ainda reviver a medida que jovens geógrafos se cansarem da dureza mental e densidade das correntes dominantes da geografia atual.

\section{Referências}

Adams, P.C., Hoelscher, S., and Till, K.E. (2001). Textures of Place. Minneapolis: University of Minnesota Press.

Alexander, C. (2012). Battle for the Life and Beauty of the Earth. New York: Oxford University Press.

Bachelard, G. (1964). The Poetics of Space. Boston: Beacon Press.

Bortoft, H. (1996). The Wholeness of Nature. Hudson, NY: Lindesfarne Press.

Brown, C.S. and Toadvine, T. (eds.) (2003). Eco-Phenomenology. Albany, New York: State University of New York Press.

Bunske, E.V. (1981). 'Humboldt and an aesthetic tradition in geography', The Geographical Review, 71: 128-145.

Buttimer, A. (1971). Society and Milieu in the French Geographic Tradition. Chicago: Rand McNally.

Buttimer, A. (1974). Values in Geography. Washington, DC: Association of American Geographers.

Buttimer, A. (1976). 'Grasping the dynamism of lifeworld', Annals of the Association of American Geographers, 66: 177-92.

\footnotetext{
43 "There is no truth, and al lis construction" (Rosenau, 1992, p. 90)

44 "The hardness of heart of the educated" (Relph, 1981, p. 107)

45 "a way of seeing that strives to omit nothing yet imposes nothing. It takes the world whole and as it is given, and attends carefully to the particularity of places and situations. It is the attempt to see clearly what there is" (Relph, 1981, p, 177).
} 
Buttimer, A. (1987). 'A social topography of home and horizon', Journal of Environmental Psychology, 7: 307-19.

Buttimer, A. (1993). Geography and the Human Spirit. Baltimore: Johns Hopkins University Press.

Buttimer, A. and Seamon, D. (1980). The Human Experience of Space and Place. London: Croom Helm.

Canter, D. and Craik, K.H. (1987) (eds.). 'Special Clark University issue', Journal of Environmental Psychology, 7: 281- 88.

Casey, E.S. (1997). The Fate of Place. Berkeley: University of California Press.

Casey, E.S. (2001a). 'Between geography and philosophy', Annals of the Association of American Geographers, 91: 683- 93.

Casey, E.S. (2001b). 'J.E. Malpas's Place and Experience', Philosophy and Geography, 4: 225-31.

Casey, E.S. (2009). Getting Back into Place, 2 nd edition. Bloomington: Indiana University Press.

Cataldi, S.L. and Hamrick, W.S. (2007). Merleau-Ponty and Environmental Philosophy. Albany, New York: State University of New York Press.

Cloke, P., Philo, C., and Sadler, D. (1991). Approaching Human Geography. London: Guildford Press.

Cressell, T. (2004). Place: A Short Introduction. Oxford: Blackwell.

Cresswell, T. (2013). Geographic Thought: A Critical Introduction. Oxford: Wiley-Blackwell.

Davis, H. (2012). Living over the Store. New York: Routledge.

Deleuze. G. and Guattari, F. (1987). A Thousand Plateaus. Minneapolis: University of Minnesota Press.

Donohoe, J. (2011). 'The place of home', Environmental Philosophy, 8 (1): 25-40.

Downs, R. and Stea, D. (1973) (eds.). Image and Environment. Chicago: Aldine.

Duncan, J. and Ley, D. (1984). 'Structural marxism and human geography: A critical perspective', Annals of the Association of American Geographers, 72: 30-59.

Entrikin, J.N. (1991). The Betweenness of Place. London: Macmillan.

Entrikin, J.N. (2001). 'Hiding places', Annals of the Association of American Geographers, 91: 694-97.

Finlay, L. (2011). Phenomenology for Therapists, Oxford: Wiley-Blackwell.

Fullilove, M.T. (2004). Root Shock. New York: Ballantine Books.

Geib, M. (ed.) (2007). Phenomenology and Ecology. Pittsburgh: Simon Silverman Phenomenology Center, Duquesne University. 
Granö, J.G. (1929/1997). Pure Geography. Baltimore: Johns Hopkins Press.

Guelke, L. (1974). 'An idealist alternative in human geography', Annals of the Association of American Geographers, 64, 193-202.

Heidegger, M. (1971). 'Building Dwelling Thinking', in Poetry, Language, and Thought. New York: Harper and Row (pp. 145-61).

Hillier, B. (1996). Space Is the Machine. Cambridge: Cambridge University Press.

Hooper, B. (2001). 'Desiring presence, romancing the real', Annals of the Association of American Geographers, 91: 703-15.

Ingold, T. (2000). The Perception of the Environment. London: Routledge.

Johnston, R.J. (1997). Geography and Geographers. London: Arnold/Hodder.

Kemmis, D. (1990). Community and the politics of place. Norman, OK: University of Oklahoma Press.

Kemmis, D. (1995). The Good City and the Good Life. New York: Houghton Mifflin.

Kogl, A. (2008). Strange Places. New York: Lexington.

Lane, B. (2000). Landscapes of the sacred. New York: Baltimore: Johns Hopkins University Press.

Larson , S.C. and Johnson, J.T. (2012). 'Toward an open sense of place: Phenomenology, affinity, and the question of being', Annals of the Association of American Geographers, 102: $632-46$.

Ley, D. (1974). The Black Inner City as Frontier Outpost. Washington, D.C.: Association of American Geographers.

Ley, D. and Samuels, W. (eds.) (1978). Humanistic Geography: Prospects and Problems. Chicago: Maaroufa Press.

Lowenthal, D. (1961). 'Geography, experience and imagination', Annals of the Association of American Geographers, 51: 241-60.

Malpas, J. (1999). Place and Experience. Cambridge: Cambridge University Press.

Malpas, J. (2001). ‘Comparing topologies', Philosophy and Geography, 4: 231-38.

Malpas, J. (2008). Heidegger and the Thinking of Place. Cambridge, Massachusetts: MIT Press.

Malpas, J. (2009). 'Place and human being', Environmental and Architectural Phenomenology, 20 (3): 19-23.

Manzo, L. and Devine-Wright, P. (eds.) (2013). Place Attachment. New York: Routledge.

Massey, D. (1991). 'A Global Sense of Place', Marxism Today, June: 24-29.

Merleau-Ponty, M. (1962). The Phenomenology of Perception, New York: Humanities Press.

Rev. Nufen: Phenom. Interd. | Belém, 9(2), 147-168, mai. - ago., 2017. 
Moores, S. (2012). Media, Place and Mobility. New York: Palgrave MacMillan.

Morris, D. (2004). The Sense of Space. Albany, New York: State University of New York Press.

Mugerauer, R. (1994). Interpretations on Behalf of Place. Albany, New York: State University of New York Press.

Mugerauer, R. (2008). Heidegger and Homecoming, Toronto: University of Toronto Press.

Murton, B. (2012). 'Being in the place world: Toward a Māori "geographical self"', Journal of Cultural Geography, 29 (1): 87-104.

Oldenburg, R. (1999). The Great Good Place, 2 nd edition, New York: Marlowe \& Company.

Peet, R. (1998). Modern Geographical Thought. Oxford: Blackwell.

Peet, R. (2000). 'Celebrating thirty years of radical geography', Environment and Planning A, 32: 951-953.

Relph, E. (1970). 'An inquiry into the relations between phenomenology and geography, Canadian Geographer, 14: 193-201.

Relph, E. (1976). Place and Placelessness. London: Pion.

Relph, E. (1981). Rational Landscapes and Humanistic Geography. New York: Barnes and Noble.

Relph, E. (2007). 'Spirit of place and sense of place in virtual realities', Techné, 10 (3): 1-8.

Relph, E. (2009). 'A pragmatic sense of place', Environmental and Architectural Phenomenology 20 (3): 24- 31.

Rose, G. (1995). Feminism and Geography. Minneapolis: University of Minnesota Press.

Rosenau, P.M. (1992). Post-Modernism and the Social Sciences. Princeton, New Jersey: Princeton University Press.

Saarinen, T., Seamon, D., and Sell, J.L. (eds.) (1984). Environmental Perception and Behavior: An Inventory and Prospect. Chicago: University of Chicago Research Paper No. 209.

Sack, R. (1997). Homo Geographicus. Baltimore: Johns Hopkins Press.

Samuels, M. (1971). Science and Geography: An Existential Appraisal. Seattle, Washington: Department of Geography, University of Washington, doctoral dissertation.

Samuels, M. (1978). 'Existentialism and human geography', in D. Ley and M. Samuels (eds.), Humanistic Geography. Chicago: Maarofa (pp. 22-40).

Seamon, D. (1979). A Geography of the Lifeworld. New York: St. Martin's.

Seamon, D. (1982). 'The phenomenological contribution to environmental psychology', Journal of Environmental Psychology, 2: 119-140. 
Seamon, D. (1987). 'Phenomenology and the Clark experience', Journal of Environmental Psychology, 7: 367-77.

Seamon, D. (2004). 'Grasping the dynamism of urban place', in T. Mels (ed.), Reanimating Places. Burlington, Vermont: Ashgate (pp. 123-45).

Seamon, D. (2008). 'Place, placelessness, insideness, and outsideness in John Sayles' Sunshine State', Aether, 3: 1- 19.

Seamon, D. (2012). 'Jane Jacobs's Death and Life of Great American Cities as a phenomenology of urban place, Journal of Space Syntax, 3: 39-49.

Seamon, D. (2013a). 'Environmental embodiment, Merleau-Ponty, and Bill Hillier's theory of space syntax: Toward a phenomenology of people-in-place, in R. Bhatt (ed.), Rethinking Aesthetics: The Role of Body in Design. New York: Routledge (pp. 204-13).

Seamon, D. (2013b). 'Lived bodies, place, and phenomenology: Implications for human rights and environmental justice', Journal of Human Rights and the Environment, 4 (2): 143-66.

Seamon, D. (2013c). 'Phenomenology and uncanny homecoming', in D. Boscaljon (ed.), Resisting the Place of Belonging, Burlington, Vermont: Ashgate (pp. 155-70).

Seamon, D. (2014a). 'Physical and virtual environments: Meaning of place and space', in B. Schell and M. Scaffa (eds.), Willard \& Spackman's Occupational Therapy, 12th Edition, Philadelphia: Wippincott, Williams \& Wilkens (pp. 202-14).

Seamon, D. (2014b). 'Place attachment and phenomenology', in L. Manzo and P. DevineWright (eds.), Place Attachment. New York: Routledge (pp. 11-22).

Seamon, D. and Mugerauer, R. (eds.) (1985). Dwelling, Place and Environment. Dordrecht: Nijhoff.

Seamon, D. and Sowers, J. (2009). 'Existential geography', in R. Kitchin and N. Thrift (eds.), International Encyclopedia of Human Geography, vol. 3. Oxford: Elsevier (pp. 666-71).

Seamon, D. and Zajonc, A. (eds.) (1998). Goethe's Way of Science: A Phenomenology of Nature. Albany, New York: State University of New York Press.

Simms, E. (2008). 'Children's lived spaces in the inner city', The Humanistic Psychologist, 36: 72-89.

Simms, E. and Stawarska, B. (2013). 'Concepts and methods in interdisciplinary feminist phenomenology', Janus Head, 13(1): 6-16.

Smith, S. (1984). 'Practicing humanistic geography', Annals of the Association of American Geographers, 74: 353- 374.

Sowers, J., (2010). A Phenomenology of Place Identity for Wonder Valley, California, doctoral dissertation. Manhattan, Kansas: Department of Geography, Kansas State University.

Stefanovic, I. (2000). Safeguarding Our Common Future. Albany, New York: State University of New York Press.

Steinbock, A. (1995). Home and Beyond. Evanston, Illinois: Northwestern University Press. 
Tilley, C. (2008). Body and Image: Explorations in Landscape Phenomenology: 2. Walnut Creek, California: Left Coast Press.

Toombs, S.K. (2001). 'The lived experience of disability', in S. K. Toombs (ed.), Handbook of Phenomenology and Medicine. Dordrecht: Kluwer (pp. 147-61).

Tuan, Y.-F. (1974a). 'Space and place: Humanistic Perspective', in C. Board, R. J. Chorley, P. Haggett, and D. R. Stoddard (eds.), Progress in Human Geography, vol. 6. London: Edward Arnold, pp. 211-152.

Tuan, Y.-F (1974b). Topophilia. Englewood Cliffs, New Jersey: Prentice-Hall.

Tuan, Y.-F. (1982). Segmented Worlds and Self. Minneapolis: University of Minnesota Press.

Tuan, Y.-F. (2012). Humanist Geography. Staunton, Virginia: George F. Thompson Press.

Wood, D. (1987). 'I don't feel that about environmental psychology today. But I want to', Journal of Environmental Psychology, 7: 417-24.

Wright, J.K. (1947). 'Terrae incognitae: The place of imagination in geography', Annals of the Association of American Geographers, 37: 1-5.

\section{Nota Biográfica}

Tradução: Letícia Carolina Teixeira Pádua (Universidade Federal dos Vales do Jequitinhonha e Mucuri)

Revisão Técnica: Eduardo José Marandola Júnior (Universidade de Campinas). 